\title{
The Race for Space!
}

\author{
Charles Jacoby, Nanette Holland, and Debbi Berger ${ }^{2}$
}

\section{UF | FLORIDIDA IFAS Extension}

The Institute of Food and Agricultural Sciences (IFAS) is an Equal

Opportunity Institution authorized to provide research, educational information and other services only to individuals and institutions that function with nondiscrimination with respect to race, creed, color, religion, age, disability, sex, sexual orientation, marital status, national origin, political opinions or affiliations. For more information on obtaining other extension publications, contact your county Cooperative Extension service.

U.S. Department of Agriculture, Cooperative Extension Service, University of Florida, IFAS, Florida A. \& M. University Cooperative Extension Program, and Boards of County Commissioners Cooperating. Larry Arrington, Dean.

\section{Copyright Information}

This document is copyrighted by the University of Florida, Institute of Food and Agricultural Sciences (UF/IFAS) for the people of the State of Florida. UF/IFAS retains all rights under all conventions, but permits free reproduction by all agents and offices of the Cooperative Extension Service and the people of the State of Florida. Permission is granted to others to use these materials in part or in full for educational purposes, provided that full credit is given to the UF/IFAS, citing the publication, its source, and date of publication.

\footnotetext{
${ }^{1}$ This document is CIR1510, an Activity in an Invasive Species Curriculum (CIR1496), and it is reprinted by permission of the Tampa Bay Estuary Program and The Florida Aquarium. Original EDIS publication date: January, 2007. It was supported by the Tampa Bay Estuary Program, the Florida Aquarium, the Department of Fisheries and Aquatic Sciences of the University of Florida, and the National Sea Grant College Program of the National Oceanic and Atmospheric Administration (NOAA), U.S. Department of Commerce, under NOAA Grant No. NA 16RG-2195. Visit the EDIS Web Site at http://edis.ifas.ufl.edu.

${ }^{2}$ Charles Jacoby, Assistant Professor, Department of Fisheries and Aquatic Sciences, Cooperative Extension Service, Institute of Food and Agricultural Sciences, University of Florida, Gainesville, 32611; Nanette Holland, Public Outreach Coordinator, Tampa Bay Estuary Program, 100 8th Avenue S.E., MS I-1 / NEP, St. Petersburg, FL 33701; Debbi Berger, Vice President of Education, The Florida Aquarium, Inc., 701 Channelside Drive, Tampa, Florida, 33602.
} 
This page was intentionally left blank. 


\section{Invasive Species \\ Series

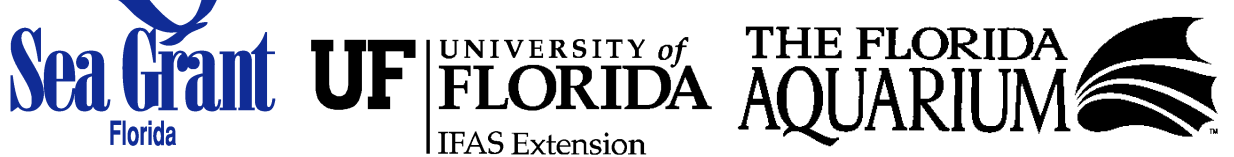

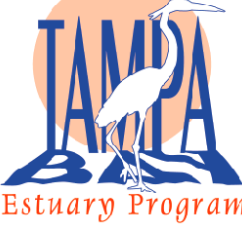 \\ The Race for Space!}

Sne ak Peek

Students will be introduced to concepts and issues

surrounding invasive species.

One specific invader in Tampa

Bay is the Asian Green

Mussel. Students will compare

how fast green mussels invade

living space normally occupied

by native species. This

activity incorporates

mathe matical calculations,

graphing, data analysis, and

environme ntal investigations.

Aligned with the following

$S$ unsfine State $S$ tandards and

$\mathcal{F C A T}$ Benchmarks for grades

$6 \cdot 8$.

$S \mathcal{C} \cdot \mathcal{D} \cdot 1.3 .3 \mathcal{C S}$

SC.F.2.3.3 CS

$S \mathcal{S C} \cdot \mathcal{D} \cdot 1.3 .4 \mathcal{A A}$

$S C . G .1 .3 .2 C S$

$S \mathcal{C} \cdot \mathcal{F} .1 .3 .1 \mathcal{A A}$

SC.G.1.3.4 $\mathcal{A A}$

$S$ C.F.1.3 7 CS

$\mathcal{A} \mathcal{A}=$ annually assessed

CS = content sampled

\section{Objectives:}

Students will...

- Calculate exponential growth.

- Formulate data to display species growth in limited living space.

- Analyze data and graph results.

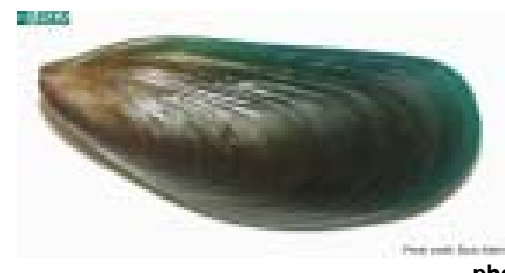

photographs from USGS

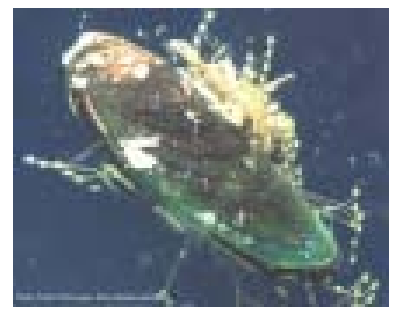

\section{Materials:}

- Pencil.

- Calculator.

- Graph paper.

- 200 blue M\&Ms, 200 red M\&Ms, and 200 yellow M\&Ms per group (other small items may be substituted, such as colored toothpicks, buttons, pipe cleaners, craft beads, etc.).

- 10 cups per group.

- 1 die per group.

\section{Background:}

Invasive species are plants or animals that are not native to a particular area and cause harm, often by disrupting natural ecosystems. There are many invasive species thriving in Florida. Invasive species may compete with native species for food and living space. A successful invader will take over space in which a native species would normally live. Eventually, invasive species may cause a loss of biodiversity by reducing the number of species found in a given area. 


\section{M ussel Explosion!}

The introduction of a plant or animal does not necessarily mean it will thrive in that environment. The success of an aquatic invader depends on many factors including water temperature, $\mathrm{pH}$, currents and water level. $O$ ne important factor is reproductive rate. A thriving invader typically has a high reproductive rate. The A sian Green Mussel is an invasive species with a high reproductive rate. It was first discovered in Tampa Bay clogging the insides of cooling water intake pipes at a power plant during the summer of 1999. The A sian G reen Mussel's current known distribution includes Tampa Bay, the west coast of Florida south to the Everglades, the Panhandle, and northeast Florida to southern Georgia. These mussels may limit biodiversity in the Tampa Bay area and elsewhere.

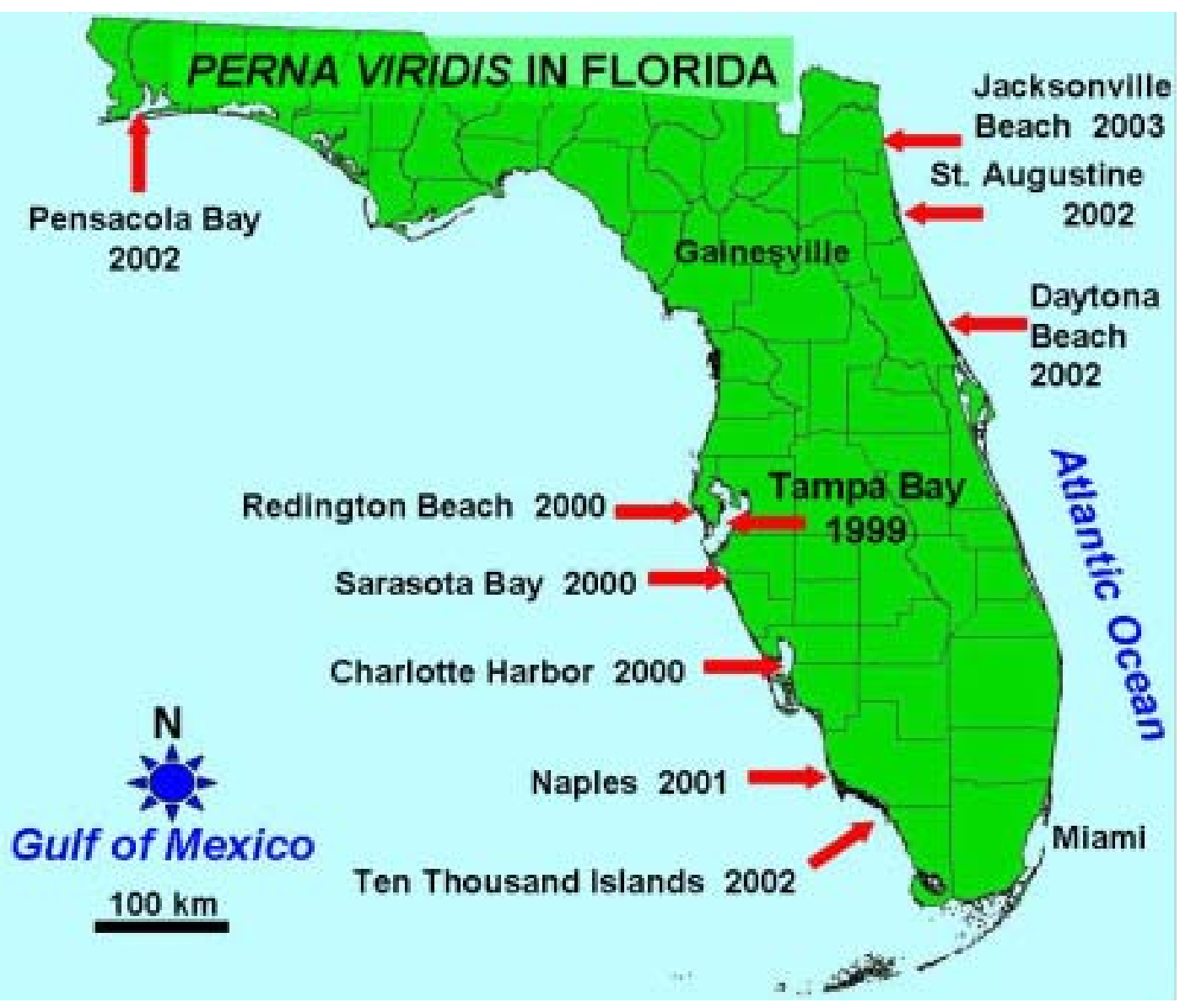

\section{Change in the distribution of Asian Green Mussel (Perna viridis) over time.}

Note: As of December 2006, the report from Pensacola Bay is not considered valid. It appears to have been a misidentification. This update provides evidence of the need for further valid information on invasive species. 


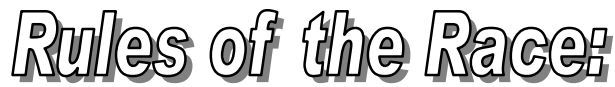

1. Separate the class into groups of three or six. Each group should form three teams representing three different species. Each team should have 200 of the same colored M\&Ms or other substituted object. Place ten cups in front of each group.

2. Team one has a survival factor of 1.25

Team two has a survival factor of 1.0

Team three has a survival factor of 0.75

*The survival factor is the ability of each species to reproduce successfully.

Team one represents Asian Green M ussels. Team two and Team three are native species. Students can pick a native bivalve species such as the Bay Scallop or Eastem Oyster.

3. Each team takes turns rolling the die. This number represents how favorable the environment is for their species, with one being least favorable and six being most favorable.

*The number on the die represents variable changes in the environment, such as changes in $\mathrm{pH}$, temperature, food availability, etc.

4. Each team has one representative from their species to start. After a member of the team rolls the die, multiply that number by the survival factor and the result by the number of individuals reproducing. For the first roll, the number of individuals reproducing is one.

5. After a team calculates the final number, round up to the nearest whole number and place that many $M \& M s$ in any cup. The cup represents living space. Only $\mathbf{2 0}$ individuals of any species can live in one cup! When a cup has 20 M\&Ms in it, the team must move to another cup.

Example:

Team one rolls a 4 on their first turn. Multiply $4 x$ $1.25 \times 1=5$. Team one then places $5 \mathcal{M e} M$ s in any cup or cups. Team one will have 5 individuals reproducing in the next round. 


\section{The next time team one rolls, they get a 2 . Multiply}

$2 \times 1.25 \times 5=12.5$ (13). Thus, team one places

13 M\&Ms in any cup or cups. *Remember only 20 M \&M s per cup!

6. Record all numbers in the attached table.

7. Once the re are $20 \mathcal{M}$ OMs in every cup, the race is over! The living space is gone! 


\section{\# OF REPRODUCING INDIVIDUALS x SURVIVAL FACTOR x ENVIRONMENTAL FAVORABLENESS}

\begin{tabular}{|c|c|c|c|}
\hline & TEAM 1 & TEAM 2 & TEAM 3 \\
\hline \# of reproducing individuals for Round 1 & 1 & 1 & 1 \\
\hline Survival factor & 1.25 & 1.0 & 0.75 \\
\hline \multicolumn{4}{|l|}{ Environmental favorableness (off die) } \\
\hline \multicolumn{4}{|l|}{ \# of individuals for cups } \\
\hline \multicolumn{4}{|l|}{ \# of reproducing individuals for Round 2} \\
\hline Survival factor & 1.25 & 1.0 & 0.75 \\
\hline \multicolumn{4}{|l|}{ Environmental favorableness (off die) } \\
\hline \multicolumn{4}{|l|}{ \# of individuals for cups } \\
\hline \multicolumn{4}{|l|}{ \# of reproducing individuals for Round 3} \\
\hline Survival factor & 1.25 & 1.0 & 0.75 \\
\hline \multicolumn{4}{|l|}{ Environmental favorableness (off die) } \\
\hline \multicolumn{4}{|l|}{ \# of individuals for cups } \\
\hline \multicolumn{4}{|l|}{ \# of reproducing individuals for Round 4} \\
\hline Survival factor & 1.25 & 1.0 & 0.75 \\
\hline \multicolumn{4}{|l|}{ Environmental favorableness (off die) } \\
\hline \multicolumn{4}{|l|}{ \# of individuals for cups } \\
\hline \multicolumn{4}{|l|}{ \# of reproducing individuals for Round 5} \\
\hline Survival factor & 1.25 & 1.0 & 0.75 \\
\hline \multicolumn{4}{|l|}{ Environmental favorableness (off die) } \\
\hline \multicolumn{4}{|l|}{ \# of individuals for cups } \\
\hline \multicolumn{4}{|l|}{ \# of reproducing individuals for Round 6} \\
\hline Survival factor & 1.25 & 1.0 & 0.75 \\
\hline \multicolumn{4}{|l|}{ Environmental favorableness (off die) } \\
\hline \multicolumn{4}{|l|}{ \# of individuals for cups } \\
\hline \multicolumn{4}{|l|}{ \# of reproducing individuals for Round 7} \\
\hline Survival factor & 1.25 & 1.0 & 0.75 \\
\hline \multicolumn{4}{|l|}{ Environmental favorableness (off die) } \\
\hline \# of individuals for cups & o & & \\
\hline \multicolumn{4}{|l|}{ \# of reproducing individuals for Round 8} \\
\hline Survival factor & 1.25 & 1.0 & 0.75 \\
\hline \multicolumn{4}{|l|}{ Environmental favorableness (off die) } \\
\hline \# of individuals for cups & & & \\
\hline
\end{tabular}

\# of reproducing individuals for each round = number of individuals placed in cups after the preceding round 
GRAP舟的

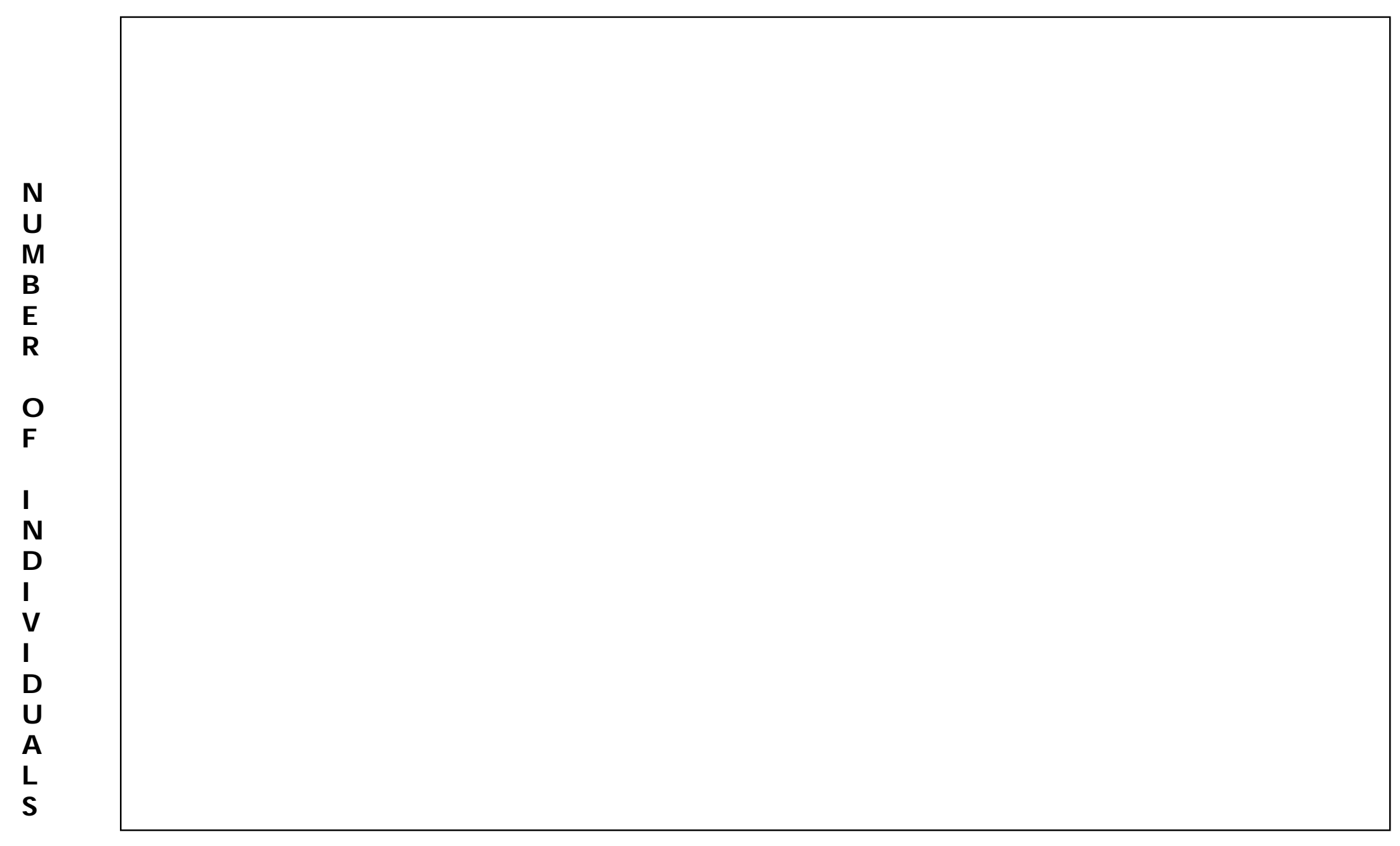

RO ULDS 


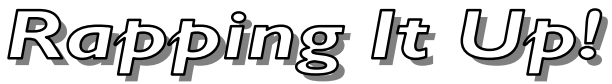

1. W hich species occupied the most living space? W hy?

2. Invasive species compete with native species for food and living space. Is there evidence in your results to suggest the Asian G reen Mussels did this? Hint: If there were no Asian Green M ussels how would your results have changed?

3. Graph the number of individuals you had for your species for each turn. Does your graph differ from the graphs of your opposing teams? How?

4. W hat are the connections between this activity and life in Tampa Bay?

5. W hat existing environmental factors may cause the invasive A sian Green Mussels to reproduce more successfully than similar native species? 


\section{Glossary:}

Aquatic- Living or growing in, on or near water.

Biodiversity - The variety of plant and animal species present in an ecosystem.

Invader/Invasive species - A plant or animal that is not native and causes harm, including disrupting natural ecosystems.

Native species - A plant or animal species that originated in a certain place. A species occurring in its natural range. Species that were present in Florida at the time the first Spanish settlers arrived. 